\title{
Estrutura de PROPRIEDADE NO BRASIL: EVIDÊNCIAS EMPÍRICAS NO GRAU DE CONCENTRAÇÃO ACIONÁRIA
}

Anamélia Borges Tannus Dami

Mestre em Administração pela FAGEN/UFU

Diretora Financeira da Jed Engenharia Elétrica Ltda

adami@triang.com.br

Pablo Rogers

Mestre em Administração pela FAGEN/UFU

Professor de Finanças da FAGEN/UFU

msc_pablo@yahoo.com.br

\section{Kárem Cristina de Sousa Ribeiro}

Doutora em Administração pela FEA/USP e

Pós-Doutora em Administração pela FEA/USP

Professora de Finanças da FAGEN/UFU

kribeiro@ufu.br

\section{RESUMO}

Este estudo investiga se existem diferenças de rentabilidade, valor de mercado, estrutura de capital, risco e tamanho do ativo em relação ao grau de concentração acionária de empresas brasileiras não-financeiras, listadas na Bovespa, entre os anos de 1997 a 2001. Como metodologia o grau de concentração acionária foi dividido em três categorias, conforme proposta de Pedersen e Thomsen (1997) - dispersa, dominante e majoritária - e analisaram-se as diferenças das variáveis investigadas entre essas categorias, pelos métodos estatísticos de Análise de Variância Paramétrica e Não-Paramétrica. Os resultados indicam que não há diferença significativa entre valor de mercado, estrutura de capital, tamanho do ativo e rentabilidade do patrimônio líquido em relação ao grau de concentração acionária. Entretanto, constataram-se diferenças estatísticas significativas entre crescimento da receita e instabilidade do mercado, com o grau de concentração acionária.

Conclui-se que em mercados instáveis há maior concentração de propriedade pela relação de dependência entre performance e concentração acionária.

Palavras-chave: Estrutura de Propriedade, Concentração Acionária, Análise de Variância Paramétrica.
ABSTRACT

This study investigates if there are profit differences, market value, structure of capital, risk and size of assets in relation to the degree of ownership concentration of non-financial Brazilian companies trading in Bovespa from 1997 to 2001. For methodological purpose, the degree of ownership concentration was divided into three categories according to Pedersen and Thomsen's (1997) proposal - disperse, dominant and majoritary - and the differences of the investigated variables were analyzed within those categories, through the statistical methods of Parametric Analysis of Variance and Non-parametric Analysis of Variance. The results indicate that there is no significant difference between market value, structure of capital, size of assets and profitability of the equity in relation to the degree of ownership concentration. However, significant statistical differences were verified between growth of the income and instability of the market, and the ownership concentration. One may conclude that there is more ownership concentration in unstable markets because of the dependence relationship between performance and ownership concentration.

Key words: Ownership Structure, Ownership Concentration, Parametric Analysis of Variance and Non-parametric Analysis of Variance. 


\section{APRESENTAÇÃO DO PROBLEMA DE PESQUISA}

A discussão sobre as causas e conseqüências da estrutura de propriedade, surgiu inicialmente, com o debate sobre a separação entre propriedade e controle das empresas modernas. Jensen e Meckling, (1976) ao desenvolverem a teoria da agência colocam que os administradores e proprietários possuem interesses e objetivos diferentes: os acionistas e proprietários desejam a maximização do valor da empresa enquanto que, os gestores buscam estratégias baseadas em sua preferência pessoal que não necessariamente coincidem com a dos proprietários, e na não existência de mecanismos e incentivos que monitorem os administradores, esses podem exercer seu livre arbítrio em detrimento dos proprietários.

A existência dos conflitos, custos de agência e direitos assimétricos coloca a necessidade de estabelecerem mecanismos de controle para que o processo de governança institua-se, de forma a harmonizar os interesses das partes envolvidas com as operações da empresa. A Figura 1 expressa essas inter-relações culminando com a apresentação de duas categorias de mecanismos de governança corporativa: mecanismos externos e mecanismos internos.
De acordo com Silveira (2002, p.14), os principais mecanismos no ambiente externo às corporações são: 1) mercado de aquisição hostil; 2) mercado de trabalho competitivo; e 3) padrões contábeis exigidos. Internamente, os principais mecanismos de controle segundo Silveira (2002, p.14) são: 1) conselho de administração; 2) sistema de remuneração dos executivos; e 3) estrutura de propriedade.

Delimitando a estrutura de propriedade como importante mecanismo interno de governança corporativa, e que práticas de governança corporativa superiores proporcionam melhor desempenho e maior valor das empresas, questiona-se: Existe relação de dependência entre o grau de concentração acionária e o valor e desempenho das empresas não-financeiras de capital aberto no Brasil?

Adicionalmente, a teoria da firma coloca que forças como o tamanho da firma, a instabilidade do mercado e a estrutura de capital exercem papel relevante sobre o grau de concentração de propriedade - essa assertiva faz surgir outro questionamento: Existe relação de dependência entre o grau de concentração
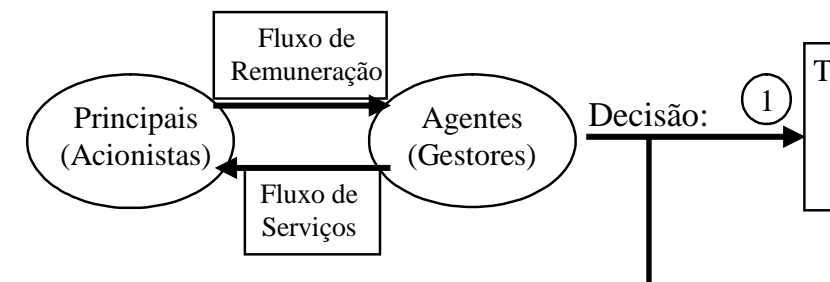

\section{Tomada de decisão que maximiza a riqueza dos acionistas

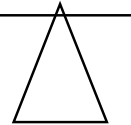 \\ Governança Corporativa - conjunto de visa harmonizar a relação entre acionistas e gestores pela redução dos custos de agência, numa situação de separação da propriedade e controle} mecanismos de incentivo e controle que

$\frac{\text { Mecanismos }}{\underline{\text { Internos }}}$
• Conselho de
Administração
- Sistemas de
remuneração
- Estrutura de
propriedade (posse
de ações pelos
gestores e

\section{$\underline{\text { Mecanismos }}$ Externos - Mercado de aquisição} hostil

- Mercado de trabalho competitivo

- Relatórios contábeis periódicos fiscalizados externamente (auditoria e agentes do mercado financeiro)
- Crescimento excessivo

こ Diversificação excessiva

- Resistência à liquidação

ou fusão vantajosa para os acionistas

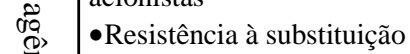

- Fixação de gastos pessoais excessivos (salários, benefícios corporativos)

$\bullet$ Roubo dos lucros

-Definição de preços de transferência ou venda de ativos abaixo do preço de mercado

-Designação de membros da família desqualificados para posições gerenciais - Obstrução do acesso ao mercado de capitais -Empreendimento de projetos devido ao seu gosto pessoal

Figura 1: Governança Corporativa e Mecanismos de Controle

Fonte: Silveira (2002, p.14). 
acionária e o tamanho da firma, a instabilidade do mercado e a estrutura de capital nas empresas brasileiras não-financeiras de capital aberto?

Esse trabalho tem por objetivo investigar os dois questionamentos supracitados, iniciando na próxima seção, sob a perspectiva da teoria da agência, a revisão bibliográfica das causas e conseqüências da estrutura de propriedade. $\mathrm{Na}$ seção 3 apresenta-se a base de dados da pesquisa, a operacionalização das variáveis utilizadas e os métodos estatísticos empreendidos para testar as hipóteses da pesquisa. A seção 4 sumaria os resultados, para na próxima concluir.

\section{ESTRUTURA DE PROPRIEDADE}

Demsetz e Lehn (1985) ao discorrerem sobre o tema estrutura de propriedade categorizam em causas e conseqüências do grau de concentração acionário. As conseqüências do grau de concentração estão associadas aos custos e benefícios para o desempenho e valor das empresas, e as causas relacionam-se com os fatores que determinam o grau de concentração, como instabilidade do mercado, tamanho da empresa e estrutura de capital.

\subsection{Conseqüências}

\section{Custos associados ao grau de concentração}

A existência de acionistas controladores pode ter efeito deletério para uma empresa devido à possibilidade dos interesses dos acionistas controladores não estarem alinhados com os interesses dos demais acionistas (SHLEIFER e VISHNY, 1997). Ademais, a concentração de direito sobre os fluxos de caixa abre caminho, além da condução de interesses próprios dentro da empresa, como nomeação e destituição dos gestores, para a impossibilidade da empresa sobre aquisição hostil.

Os acionistas controladores podem expropriar a riqueza dos outros acionistas de várias formas: 1) pagamentos de salá- rios excessivos para si; 2) autonomeação em cargos executivos privilegiados e posições no conselho para si ou familiares e parentes (nepotismo); 3) pagar ou receber preços de transferências altos para empresas das quais são proprietários; 4) transferência de ações com deságio ou o ato de insider trading; 5) utilizar ativos da empresa como garantia de transações pessoais ou tomar emprestados fundos da empresa com vantagens comerciais; 6) propensão a prática de sub-investimentos, pois se os investimentos não forem recuperados os custos serão divididos em partes iguais com todos os acionistas (JENSEN e MECKLING, 1976); e 7) alocação de recursos em projetos de investimentos que reduzem seus riscos e não a maximização de riqueza da empresa.

De acordo com Andrade e Rossetti (2004, p.126), os benefícios privados do controle podem levar investidores a se assegurarem de retornos através de mecanismos que lhes confiram o controle corporativo. Segundo os autores, os mais comuns são:

1. Emissões de ações com direitos de voto limitados (ações preferenciais);

2. Propriedade cruzada de ações de duas ou mais empresas dificultando a perda de controle;

3. Estrutura piramidal, através de holdings que, por sua vez, detêm a propriedade de empresas-alvo objeto de controle.

Claessens et al. (2002) resumem os custos da concentração acionária como um efeito entrincheiramento, quando da posse e concentração de votos da empresa (Figura 2). No efeito entrincheiramento, o aumento da parcela de votos e de propriedade da empresa detida pelo controlador, faz com que o mesmo esteja menos dependente e sujeito às decisões do conselho de administração e ao mercado de fusões e aquisições, permitindo a expropriação de riqueza para o benefício privado, enquanto os custos seriam compartilhados entre todos os acionistas.

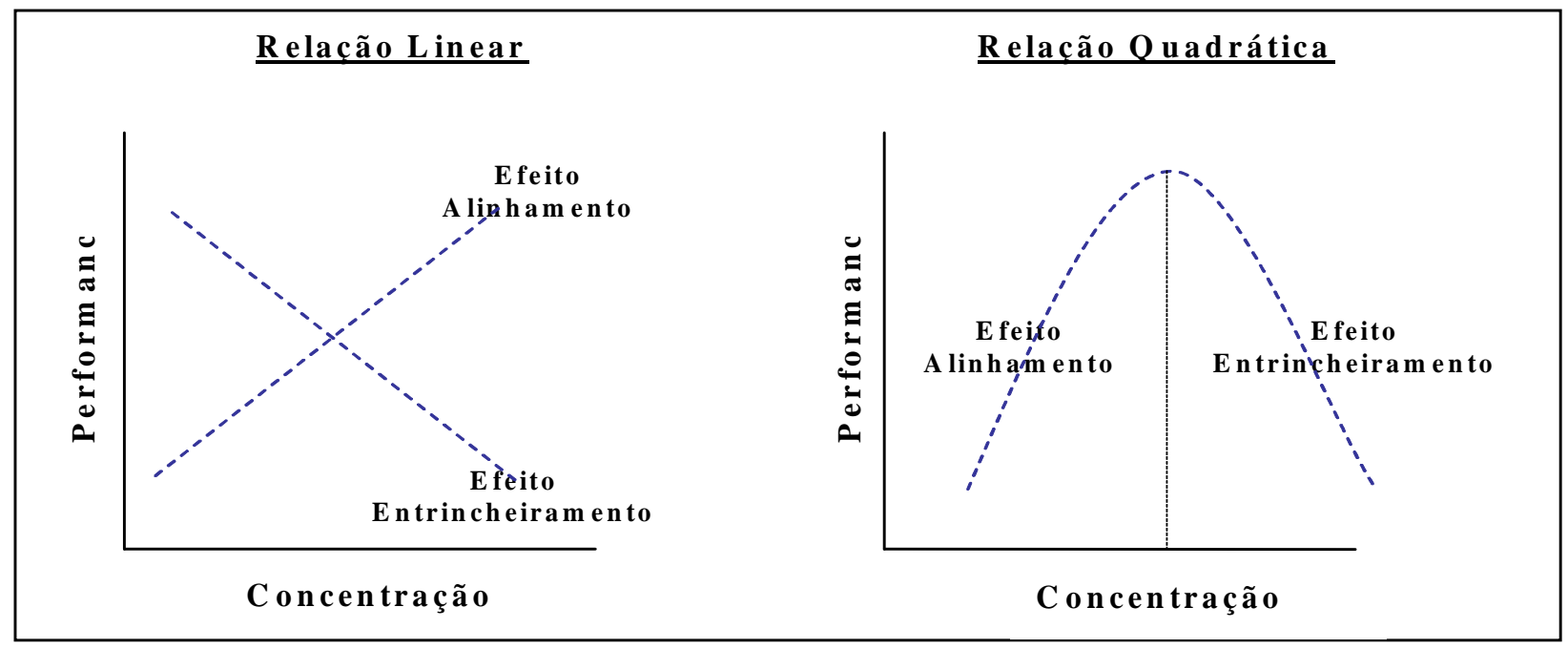

Figura 2: Efeitos Entrincheiramento e Alinhamento no Grau de Concentração Acionária.

Fonte: Elaboração própria 


\section{Benefícios associados ao grau de concentração}

As vantagens mais importantes direcionadas à concentração de propriedade estão ligadas à possibilidade dos proprietários monitorar a administração com a provável redução de conflitos e custos de agência. Hitt, Ireland e Hoskisson (2002, p.411) observam que,

\begin{abstract}
Em geral, a propriedade difusa (um grande número de acionistas com um número pequeno de ações (holdings) e poucos, se houver, acionistas portadores de grandes lotes) produz uma fraca monitoração das decisões administrativas. Entre outros problemas, a propriedade difusa torna difícil aos proprietários a coordenação de suas ações de forma eficiente. Um resultado da fraca monitoração poderia ser uma diversificação das linhas de produto da firma além do nível ótimo para os acionistas. Níveis mais elevados de monitoração poderiam encorajar os gerentes a evitar decisões estratégicas que não criam maior valor para os acionistas.
\end{abstract}

Okimura (2003, p.29) e Andrade e Rossetti (2004, p.126) salientam que há evidencias empíricas que mostram que a presença de acionistas controladores aumenta a relação benefícios/ custos do monitoramento, implicando soluções otimizadas para a questão dos conflitos de agência. La Porta et al. (1998 e 1999) argumentam que a existência de acionistas controladores é uma tentativa de se minimizar os conflitos de agência em países com baixa proteção legal e institucional dos investidores. $\mathrm{O}$ ponto principal da argumentação é de que em ambientes de baixa proteção, a única forma de equilibrar os interesses seria a existência de um acionista controlador, o que permitiria uma sinalização de comprometimento a investidores externos de que os acionistas controladores não desviariam os ativos da empresa.

Esta sinalização seria positiva para investidores externos devido ao fato de que a avaliação de preços de ações são baseados nas expectativas de expropriação ex-post pelos acionistas controladores. Se os acionistas controladores expropriam o fluxo de caixa da empresa, os investidores externos irão apreçar as ações com um prêmio de desconto e conseqüentemente os acionistas controladores terão suas ações com valor destruído (OKIMURA, 2003, p.29).

Claessens et al. (2002) resumem os benefícios da concentração acionária como um efeito alinhamento, quando da posse e concentração de votos da empresa (Figura 2). No efeito alinhamento, à medida que a parcela de ações detida pelo controlador aumenta, aumentam os incentivos para monitoramento ao mesmo tempo em que aumentam os custos de expropriação. Nesse ponto, a posse de uma grande parcela das ações traz o comprometimento do controlador em não desvalorizar os papéis da empresa, pois reduziria substancialmente sua riqueza: isso seria um alto custo e comparável com os possíveis benefícios privados de expropriação da empresa.

\subsection{Causas}

Siqueira (1998, p.1) coloca que várias pesquisas a partir dos anos 80, considerando companhias européias, norte-ame- ricanas e asiáticas, têm testado as hipóteses de que forças como o tamanho da firma, instabilidade dos mercados de atuação e estrutura de capital da empresa exercem papel relevante sobre o grau de concentração da propriedade.

\section{Tamanho da Firma}

De acordo com Siqueira (1998, p.4), as companhias de grande porte podem ser associadas com elevados custos de capital e com alto risco de manutenção do grau de concentração do controle acionário - em função da aversão ao risco, as grandes empresas tenderiam a apresentar uma baixa concentração da propriedade.

Demsetz e Lehn (1985, p.1158) argumentam que o tamanho das empresas varia dentro do setor e entre os vários setores, de forma que quanto maior o tamanho viável da empresa, dependendo assim de sua posição e competitividade em seu mercado, maior a disponibilidade de recursos, e maior o valor de mercado de uma parcela de sua propriedade. De acordo com Okimura (2003, p.34), isso influenciaria a concentração de propriedade de forma inversa, visto que, quanto maior o valor de mercado e maior o valor absoluto da empresa, menor a probabilidade e a possibilidade de uma parcela maior da propriedade serem detidas por um acionista controlador.

\section{Instabilidade do Mercado}

A instabilidade do mercado exerce influência sobre a concentração da propriedade em função do conflito de interesses entre administradores e proprietários (SIQUEIRA, 1998, p.4). Dessa forma, o conflito de interesses seria menor ou maior dependendo da instabilidade dos mercados. A redução do grau de instabilidade de mercado (associada com mudanças de preços, tecnologia e market-share) provoca a redução da concentração da propriedade, podendo, inclusive, aumentar a liberdade de monitoramento dos gestores.

Segundo Siqueira (1998, p.4),

(...) a forma de mensuração desse efeito (...) pode ser alguma medida de instabilidade do desempenho econômico-financeiro das empresas, tal como um indicador de rentabilidade. Uma elevada variação da rentabilidade durante um certo período poderia proporcionar o aumento do conflito entre administradores e proprietários e provocar, por conseguinte, uma mudança na estrutura da propriedade (...) o grau de concentração da propriedade tende a ser elevado em mercados com elevada instabilidade, com os controladores mantendo-se, inclusive, à frente dos negócios.

\section{Estrutura de Capital}

A estrutura de capital afeta negativamente ou positivamente a concentração de propriedade. A hipótese de Pedersen e Thomsen (1997), é que o aumento da relação (patrimônio líquido/ativo total), ou de outra forma, o aumento do capital próprio investido na empresa seja acompanhado pela redução da concentração da propriedade das empresas, devido, principalmente, o objetivo de compartilhar os riscos dos acionistas controladores. Siqueira (1998, p.11) apresenta que a estrutura de 
capital das empresas pode ter “(...) efeito positivo sobre a concentração da propriedade, indicando que, quanto maior os investimentos específicos em plantas de grandes escalas, maior deverá ser a concentração do controle acionário".

\subsection{Concentração Acionária no Brasil}

No Brasil a estrutura da propriedade acionária é, predominantemente, concentrada contribuindo sobremaneira para o principal conflito de agência existente no país: entre acionistas minoritários e acionistas majoritários.

Siffert Filho (1998), em levantamento feito com as 100 maiores empresas por receita operacional líquida nos anos de 1990, 1995 e 1997, levando-se em consideração a classificação de propriedade de Thomsen e Pedersen (1997), concluiu que a estrutura de propriedade está concentrada nas mãos de famílias ou de multinacionais estrangeiras. Dado esse fato, a estrutura de propriedade apresenta-se como o principal e mais estudado mecanismo interno de governança corporativa no Brasil.

As grandes transformações que ocorreram na economia nacional - abertura econômica e privatizações - implicaram em mudanças mais na identidade dos controladores do que no grau de concentração (SIFFERT FILHO, 1998). A Tabela 1 apresenta resultados de amostras significativas das empresas listadas na Bovespa, para os anos de 1998 a 2002, segundo levantamento realizado por Okimura, Silveira e Rocha (2004). Os resultados de levantamentos com dados do inicio dos anos 90 e da virada do século não são significativamente diferentes quanto à presença de controladores majoritários (ANDRADE e ROSSETTI, 2004, p.315). Segundo Leal et al. (2000) e Carvalhalda-Silva (2004) o controle das empresas é dominado em média pelos três maiores acionistas: tendo mantido, de acordo com

Tabela 1: Grau de concentração das empresas brasileiras

\begin{tabular}{ccc}
\hline Anos & $\begin{array}{c}\text { Ações ordinárias do } \\
\text { controlador (ou } \\
\text { grupo de controle) } \\
\text { em relação ao total } \\
\text { das ações ordinárias } \\
\text { emitidas }\end{array}$ & $\begin{array}{c}\text { Açes ordinárias e } \\
\text { preferenciais do } \\
\text { controlador (ou } \\
\text { grupo de controle) } \\
\text { em relação ao total } \\
\text { de emissões }\end{array}$ \\
\hline 1998 & $75,7 \%$ & $52,0 \%$ \\
1999 & $75,5 \%$ & $53,5 \%$ \\
2000 & $76,1 \%$ & $54,0 \%$ \\
2001 & $77,3 \%$ & $54,6 \%$ \\
2002 & $76,2 \%$ & $54,6 \%$ \\
\hline Média & $\mathbf{7 6 , 1 \%}$ & $\mathbf{5 3 , 7 \%}$ \\
Mediana & $\mathbf{7 9 , 5} \%$ & $\mathbf{5 1 , 5 \%}$ \\
Desvio-Padrão & $\mathbf{2 0 , 0} \%$ & $\mathbf{2 4 , 6 \%}$ \\
\hline
\end{tabular}

Fonte: Adaptado de Okimura, Silveira e Rocha (2004).
Andrade e Rossetti (2004, p.315), uma participação superior a $80 \%$ do capital votante na maioria das grandes companhias.

De acordo com a Tabela 1 , as ações ordinárias mantidas pelo controlador (ou grupo de controle) chegam a 76,1\% na média do período 1998/2002 em relação ao total das ações com direito a voto emitidas. Adicionando a essas ações as preferenciais de propriedade do grupo de controle, a relação com o total das emissões cai para 53,7\% evidenciando assim, uma discrepância entre o direito à propriedade e ao fluxo de caixa da empresa. Observa-se ainda na tabela, que a concentração, tanto das ações ordinárias em relação ao total de ações quanto das ações ordinárias mais as preferências em relação ao total de ações, aumentou levemente no período analisado.

Com dados referentes ao ano de 2000, Carvalhal-da-Silva (2004) evidenciou que $90,2 \%$ das empresas pesquisadas possuíam um acionista majoritário e apenas $9,8 \%$ apresentavam estruturas mais dispersas de propriedade, mais ainda assim com participação dominante do maior acionista (Tabela 2). Nas companhias com acionista majoritário, o maior acionista detinha $76 \%$ do capital votante; os três maiores, $88 \%$; os cinco maiores, $89 \%$. Evidencia-se também na Tabela 2, o alto grau de concentração nas companhias sem acionista majoritário: nestas, o maior acionista detinha $37 \%$; os três maiores, $62 \%$; os cinco maiores, $66 \%$.

Tabela 2: Composição acionária direta das companhias brasi leiras em 2000

\begin{tabular}{|c|c|c|c|c|c|c|}
\hline \multirow[t]{2}{*}{ Acionista } & \multicolumn{2}{|c|}{$\begin{array}{c}\text { Companhias } \\
\text { Com Acionista } \\
\text { Majoritário } \\
\text { (203) }\end{array}$} & \multicolumn{2}{|c|}{$\begin{array}{c}\text { Companhias } \\
\text { Sem Acionista } \\
\text { Majoritário (22) }\end{array}$} & \multicolumn{2}{|c|}{$\begin{array}{c}\text { Total da } \\
\text { Amostra (225) }\end{array}$} \\
\hline & $\begin{array}{r}\text { Capital } \\
\text { Votante }\end{array}$ & $\begin{array}{c}\text { Capital } \\
\text { Total }\end{array}$ & $\begin{array}{l}\text { Capital } \\
\text { Votante }\end{array}$ & $\begin{array}{c}\text { Capital } \\
\text { Total }\end{array}$ & $\begin{array}{l}\text { Capital } \\
\text { Votante }\end{array}$ & $\begin{array}{c}\text { Capital } \\
\text { Total }\end{array}$ \\
\hline Maior & $76 \%$ & $54 \%$ & $37 \%$ & $23 \%$ & $72 \%$ & $51 \%$ \\
\hline $\begin{array}{c}\text { Três } \\
\text { Maiores }\end{array}$ & $88 \%$ & $65 \%$ & $62 \%$ & $41 \%$ & $85 \%$ & $62 \%$ \\
\hline $\begin{array}{c}\text { Cinco } \\
\text { Maiores }\end{array}$ & $89 \%$ & $65 \%$ & $66 \%$ & $44 \%$ & $87 \%$ & $63 \%$ \\
\hline
\end{tabular}

Fonte: Adaptado de Carvalhal-da-Silva (2004).

Nota: Composição acionária direta média da 225 companhias brasileiras listadas na Bovespa.Uma companhia com um acionista majoritário é aquela na qual um acionista possui mais de $50 \%$ do capital votante. $\mathrm{N}^{\circ}$ de empresas em cada grupo entre parênteses

\section{METODOLOGIA DA PESQUISA}

\subsection{Levantamento dos Dados}

No mês de maio de 2001 haviam 459 empresas listadas na Bolsa de Valores de São Paulo (Bovespa), sendo que 289 possuíam dados disponíveis no Banco de dados da 
Economática ${ }^{\circledR}$. Para desenvolvimento do estudo, foram consideradas todas as empresas não-financeiras de capital aberto com ações negociadas na Bovespa, com dados disponíveis para, pelo menos, três dos cinco anos estudados (1997 a 2001) resultando em um total de 176 empresas.

\subsection{Operacionalização das Variáveis}

De acordo com Okimura (2003, p.44), ainda não há na literatura acadêmica unanimidade sobre a escolha de medidas de estrutura de propriedade e controle para a análise do desempenho e valor das empresas. A escolha da medida apropriada, de acordo com o autor, depende da disponibilidade dos dados e de sua adequação à aplicabilidade da mesma. Autores que estudam a concentração de propriedade em países em desenvolvimento, como o fazem Okimura (2003), Okimura, Silveira e Rocha (2004) e Siqueira (1998) no Brasil, tendem a utilizar diretamente a concentração de ações em forma percentual somente do maior acionista.

Na presente pesquisa a concentração acionária ou concentração dos direitos de controle foi categorizada em três classes segundo o grau de propriedade, como proposto por Pedersen e Thomsen (1997) e Siqueira (1998):

- Dispersa: quando o maior acionista detém menos de $20 \%$ do controle;

- Dominante: quando o maior acionista detém entre $20 \%$ e $50 \%$ do controle;

- Majoritária: quando o maior acionista detém mais de $50 \%$ do controle

As métricas usadas para aferir o desempenho ainda não são unânimes no meio acadêmico. Dentre as mais empregadas, de acordo com Barney (1997), quatro categorias se destacam: a) sobrevivência (como medidas de fluxo de caixa); b) os indicadores contábeis de desempenho; c) as medidas de criação de valor para os stakeholders e; d) medidas de valor presente líquido. Para a pesquisa foram consideradas às medidas dos grupos b) e c).

Como métrica de desempenho por meio dos indicadores contábeis usou-se, assim como também Demsetz e Lehn (1985) e Siqueira (1998), a rentabilidade do patrimônio liquido (RPL), definido de acordo com relação estabelecida na equação 1 , e a taxa de crescimento da receita líquida em reais nominais (CRL), como expresso na equação 2 .

$$
\mathrm{RLP}_{\mathrm{i}}=\frac{\mathrm{LL}_{\mathrm{i}}}{\mathrm{PL}_{\mathrm{i}}}
$$

Onde, $\mathrm{LL}_{\mathrm{i}}$ é o lucro líquido da empresa $i$ e $\mathrm{PL}_{\mathrm{i}}$ expressa o valor contábil do patrimônio líquido da empresa $i$.

$$
\mathrm{CRL}=\frac{\text { Vendas }_{\mathrm{i}-1}-\text { Vendas }_{\mathrm{i}}}{\text { Vendas }_{\mathrm{i}}}
$$

Como medida de criação de valor para os acionistas priorizou-se o Q de Tobin (Q), definido de acordo com a relação estabelecida na equação 3. Essa medida é definida por Chung e Pruit (1994, p.72) e discutida por Famá e Barros (2000) como uma aproximação do que inicialmente foi proposto por Tobin e Brainard (1968) apud Okimura (2003, p.47). A essência dessa medida é a de que os custos de reposição sejam uma medida razoável para os valores de usos alternativos dos ativos, pois o valor das empresas por esse indicador é definido como a razão entre o valor de mercado das ações e dívidas pelo custo de reposição dos ativos (OKIMURA, 2003, p.47).

$$
\mathrm{Q}=\left(\frac{\mathrm{VMO}+\mathrm{VMAP}+\mathrm{DIVT}}{\mathrm{AT}}\right)
$$

Onde, $\mathrm{VMO}=$ valor de mercado das ações ordinárias; VMAP $=$ valor de mercado das ações preferenciais; DIVT $=$ valor contábil das dívidas de curto e longo prazo menos o ativo circulante, após a exclusão do valor dos estoques; e AT = valor contábil do ativo total. Todas as variáveis observadas no final do ano $t$.

O tamanho da empresa é definido como o valor contábil nominal do ativo total (AT) assim como utilizado por Demsetz e Lehn (1985), Pedersen e Thomsen (1997), Demsetz e Vilalonga (2001) e Siqueira (1998). Demsetz e Lehn (1985), Pedersen e Thomsen (1997) e Demsetz e Vilalonga (2001) identificaram um efeito negativo do tamanho da firma sobre o grau de concentração do controle acionário, ou seja, segundo os estudos o aumento do tamanho da firma proporciona maior dispersão do controle acionário. Entretanto, para o Brasil, Siqueira (1998) encontrou uma relação positiva entre tamanho da firma e grau de concentração do controle acionário.

Como proxy da instabilidade da rentabilidade foi utilizado o desvio-padrão da rentabilidade do patrimônio liquido (INST) para o período em análise. Essa proxy também foi utilizada por Demsetz e Lehn (1985), Pedersen e Thomsen (1997), Demsetz e Vilalonga (2001) e Siqueira (1998). No Brasil, Siqueira (1998) não identificou uma relação estatisticamente significativa entre essa variável e a concentração do controle acionário diferentemente dos resultados encontrados por Demsetz e Lehn (1985) e Pedersen e Thomsen (1997), os quais identificaram correlação positiva entre a instabilidade da rentabilidade e a concentração da propriedade, ou seja, que o aumento da instabilidade gera aumento da concentração do controle de propriedade.

A estrutura de capital (ESTCAP) é definida de acordo com a relação estabelecida na equação 4. Essa variável é utilizada nos modelos desenvolvidos por Siqueira (1998) para a economia brasileira. Demsetz e Vilalonga (2001), Okimura (2003), Okimura, Silveira e Rocha (2004), Silveira (2004) e Silveira, Barros e Famá (2005) fazem uso dessa variável de controle para estudarem as relações entre desempenho e estruturas de governança, entretanto consideram como proxy o valor das dívidas sobre o ativo total (alavancagem) o que equivale aproximadamente, a um menos a variável ESTCAP considerada por Siqueira (1998) e aqui priorizada.

$$
\mathrm{ESTCAP}=\frac{\mathrm{PL}_{\mathrm{i}}}{\mathrm{AT}_{\mathrm{i}}}
$$

Onde, $\mathrm{PL}=$ valor contábil do patrimônio líquido da empresa i; e AT = valor contábil do ativo total da empresa i.

Observa-se ainda, que na classificação do grau de propriedade em dispersa, dominante e majoritária foi considerada a posição das empresas em 2001 e para a operacionalização da 
instabilidade do mercado, o desvio-padrão da rentabilidade do patrimônio liquido no período de 1997 a 2001. Para as outras variáveis, utilizou-se a média do período analisado (1997 a 2001).

\subsection{Técnicas Estatísticas Utilizadas}

Os procedimentos empregados serão a Análise de Variância Paramétrica (ANOVA) ${ }^{1}$ e/ou o Teste Kruskal-Wallis ${ }^{2}$ (Análise de Variância Não-Paramétrica) considerando como fator a categorização da concentração acionária em três classes segundo o grau de propriedade, como proposto por Pedersen e Thomsen (1997) e Siqueira (1998).

O uso da ANOVA depende da suposição de normalidade dos resíduos e homogeneidade das variâncias sendo que testadas essas hipóteses e não confirmadas o procedimento da ANOVA torna-se não robusto estatisticamente. O teste KruskalWallis é um teste para analisar se $k$ amostras independentes provêm de distribuições diferentes assim como a ANOVA, porém tal teste não faz suposições sobre os parâmetros das distribuições, ou seja, esse é um teste não-paramétrico que pode ser em- de capital nas empresas brasileiras não-financeiras de capital aberto; $\mathrm{H}_{0,5}$ : não há relação entre grau de concentração e a instabilidade de mercado nas empresas brasileiras não-financeiras de capital aberto;

$\mathrm{H}_{0,6}$ : não há relação entre grau de concentração e o tamanho do ativo nas empresas brasileiras não-financeiras de capital aberto;

\section{RESULTADOS DA PESQUISA}

As estatísticas descritivas das variáveis apresentadas na Tabela 3 indicam uma alta variabilidade dos dados o que, por conseguinte, direciona para a heterogeneidade das variâncias. Os teste estatísticos empregados tem como objetivo analisar se as médias das variáveis de performance (RPL, CRL e Q), tamanho da empresa (AT), estrutura de capital (ESTCAP) e instabilidade da rentabilidade (INST) são diferentes entre os grupos de concentração: dispersa, dominante e majoritária. Nesse sentido, o intuito torna-se encontrar evidências da relação entre concentração de propriedade com a performance das empresas e com as outras variáveis relacionadas com a concentração de propriedade que a literatura indica.

Tabela 3: Estatísticas Descritivas das Variáveis da Pesquisa por Grau de Concentração

\begin{tabular}{ccccccc}
\hline & \multicolumn{2}{c}{ DISPERSA } & \multicolumn{2}{c}{ DOMINANTE } & \multicolumn{2}{c}{ MAJORITÁRIA } \\
\cline { 2 - 6 } & Média & Desvio-Padrão & Média & Desvio-Padrão & Média & Desvio-Padrão \\
\hline RPL & $-9,22$ & 17,4 & $-2,28$ & 20,04 & $-17,04$ & 48,31 \\
CRL & 0,63 & 26,17 & 13,13 & 26,81 & 10,69 & 17,96 \\
Q & 0,3 & 0,26 & 0,33 & 0,34 & 0,4 & 0,36 \\
ESTCAP & 0,42 & 0,26 & 0,45 & 0,19 & 0,4 & 0,22 \\
AT & 873243,52 & 937721,22 & 1812586,84 & 3516032,4 & 1553066,01 & 5437509,82 \\
INST & 23,36 & 26,42 & 19,35 & 30,4 & 36,14 & 54,32 \\
\hline
\end{tabular}

Fonte: Elaboração Própria

pregado em dados (resíduos) que não apresentam normalidade e/ou variâncias muito diferentes (CONOVER, 1980, p.229-239).

Para testar a homogeneidade das variâncias e a normalidade dos dados serão aplicados respectivamente, os testes de Levene e Kolgomorov-Smirnov. Caso rejeitado uma das duas hipóteses, será aplicado o teste Kruskal-Wallis caso contrário, proceder-se-á a ANOVA visto que, sob essas duas hipóteses a ANOVA é mais robusta estatisticamente.

Tecnicamente, as hipóteses a serem testadas podem ser formuladas como:

$\mathrm{H}_{0,1}$ : não há relação entre grau de concentração e o crescimento da receita líquida nas empresas brasileiras não-financeiras de capital aberto;

$\mathrm{H}_{0,2}$ : não há relação entre grau de concentração e a rentabilidade do patrimônio líquido nas empresas brasileiras não-financeiras de capital aberto;

$\mathrm{H}_{0,3}$ : não há relação entre grau de concentração e o valor das empresas, medido pelo Q de Tobin, nas empresas brasileiras não-financeiras de capital aberto;

$\mathrm{H}_{0,4}$ : não há relação entre grau de concentração e a estrutura
Como exposto na metodologia, para comprovar a hipótese de normalidade e homogeneidade procederam-se os testes de Kolmogorov-Smirnov e Levene, respectivamente. Esses, para as variáveis analisadas encontram-se na Tabela 4 .

Tabela 4: Teste de Homogeneidade e Normalidade

\begin{tabular}{ccccc}
\hline Variável & Levene Test & p-value & $\begin{array}{c}\text { Kolgomorov- } \\
\text { Smirnov Test }\end{array}$ & p-value \\
\hline Q & 0,683 & 0,507 & 0,465 & 0,982 \\
\hline R P L & 12,772 & 0,000 & 2,840 & 0,000 \\
\hline C R L & 1,383 & 0,254 & 2,009 & 0,001 \\
\hline E S T A P & 0,445 & 0,641 & 0,763 & 0,606 \\
\hline A T & 0,413 & 0,662 & 4,905 & 0,000 \\
\hline IN S T & 4,62 & 0,011 & 3,502 & 0,000 \\
\hline
\end{tabular}

Fonte: Elaboração Própria

Conforme evidenciado na Tabela 4 rejeita-se a hipótese de homogeneidade das variâncias das variáveis RPL e INST com $5 \%$ de significância, assim como também rejeita-se a hipótese de normalidade para as variáveis RPL, CRL, AT e INST com 1\% de 
significância. Dessa forma, conforme a metodologia, procederse-á para testar a diferença entre os grupos (dispersa, dominante e majoritária) o Teste ANOVA para as variáveis Q e ESTCAP e o Teste Kruskal-Wallis para as variáveis RPL, CRL, AT e INST.

Conforme os testes apresentados nas Tabelas 5 a 7 rejeitase a igualdade das médias para os grupos de concentração dispersa, dominante e majoritária para a variável CRL a 10\% de significância e para variável INST a 5\% de significância - ambas hipóteses rejeitadas pelo teste Kruskal-Wallis. Pelos testes empregados não foi possível rejeitar as hipóteses $\mathrm{H}_{0,2} \mathrm{H}_{0,3} \mathrm{H}_{0,4}$ $\mathrm{H}_{0,6}$, ou seja, as evidências estatísticas permitem aceitar que não há relação entre o grau de concentração e rentabilidade do patrimônio líquido, Q de Tobin (valor das empresas), estrutura de capital e tamanho do ativo.

Tabela 5: Teste ANOVA para Q e ESTCAP

\begin{tabular}{|c|c|c|c|c|c|c|}
\hline V a riável & & $\begin{array}{l}\text { Sum of } \\
\text { Squares }\end{array}$ & $\mathrm{df}$ & $\begin{array}{c}\text { Mean } \\
\text { Square }\end{array}$ & F & P-V alue \\
\hline \multirow{3}{*}{ Q } & $\begin{array}{l}\text { Between } \\
\text { Groups }\end{array}$ & 0,200 & 2 & 0,100 & 0.800 & 0,451 \\
\hline & $\begin{array}{l}\text { W ithin } \\
\text { Groups }\end{array}$ & 20,465 & 164 & 0,125 & & \\
\hline & Total & 20,664 & 166 & & & \\
\hline \multirow{3}{*}{ ESTCAP } & $\begin{array}{l}\text { Between } \\
\text { Groups }\end{array}$ & 0,099 & 2 & 0,049 & 1,070 & 0,345 \\
\hline & $\begin{array}{l}\text { W ithin } \\
\text { Groups }\end{array}$ & 7,903 & 171 & 0,046 & & \\
\hline & Total & 8,002 & 173 & & & \\
\hline
\end{tabular}

Fonte: Elaboração Própria

Tabela 6: Ranks Kruskal-Wallis Test - RPL, CRL, AT e IN

\begin{tabular}{clcc}
\hline Variável & $\begin{array}{c}\text { Classificação } \\
\text { Concentração de } \\
\text { Propriedade }\end{array}$ & N & Mean Rank \\
\hline \multirow{2}{*}{ RPL } & Dispersa & 10 & 73,70 \\
& Dominante & 53 & 96,66 \\
& Majoritária & 113 & 85,98 \\
& Total & 176 & \\
\hline \multirow{4}{*}{ CRL } & Dispersa & 10 & 63,70 \\
& Dominante & 53 & 97,98 \\
& Majoritária & 112 & 85,45 \\
& Total & 175 & \\
\hline \multirow{2}{*}{ AT } & Dispersa & 10 & 90,50 \\
& Dominante & 53 & 94,24 \\
& Majoritária & 113 & 85,58 \\
& Total & 176 & \\
\hline \multirow{2}{*}{ INST } & Dispersa & 10 & 97,10 \\
& Dominante & 53 & 72,72 \\
& Majoritária & 113 & 95,14 \\
& Total & 176 & \\
\hline
\end{tabular}

Fonte: Elaboração Própria
Os resultados indicam a existência de relação entre concentração de propriedade e crescimento da empresa (CRL) e instabilidade de sua rentabilidade (INST). Ao analisar a Tabela 3 , considerando o crescimento da receita líquida como medida de performance, nota-se que a variável CRL é menor para empresas dispersas $(0,63)$ e maior para empresas dominantes $(13,13)$. Quando a concentração acionária muda de dominante para majoritária, a variável CRL tem um decréscimo (13,13 para 10,69), direcionando para uma relação quadrática entre concentração e performance, onde há primeiramente um efeito alinhamento e posteriormente um efeito entrincheiramento .

Tabela 7: Statistics Kruskal-Wallis Testa, b - RPL, CRL, AT e INST

\begin{tabular}{lcccc}
\hline & RPL & CRL & AT & INST \\
\hline Chi-Square & 2,479 & 4,642 & 1,082 & 7,291 \\
df & 2 & 2 & 2 & 2 \\
P-value. & 0,289 & 0,098 & 0,582 & 0,026 \\
\hline
\end{tabular}

Fonte: Elaboração Própria

a. Kruskal Wallis Test

b. Grouping Variable: Dispersa, Dominante e Majoritária

Em relação à instabilidade do mercado os resultados encontrados estão de acordo com Demsetz e Lehn (1985) e Pedersen e Thomsen (1997), os quais identificaram correlação positiva entre a instabilidade da rentabilidade e a concentração da propriedade, ou seja, que a concentração de propriedade é maior quando maior for a instabilidade do mercado. A Tabela 3 identifica que a variável INST possui uma média de 23,16 para empresas dispersas e 36,14 para empresas da categoria majoritária.

$1 \mathrm{O}$ efeito entrincheiramento pode ser questionado, uma vez que essas médias estão muito próximas. Entretanto, há evidencias suficientes para se aceitar o efeito alinhamento, já que a média das empresas dispersas é significativamente menor do que as empresas dominantes e majoritárias.

\section{CONCLUSÕES}

A separação da propriedade e gestão e a pulverização acionária fazem surgir conflitos de interesses entre os acionistas e gestores e, em países com baixa proteção legal, entre acionistas minoritários e majoritários. Os direitos assimétricos existentes entre minoritários e majoritários produzem custos de agência, colocando a necessidade de mecanismos ex-ante, para monitoramento e controle de tais custos. Os mecanismos de controle podem ser internos e externos a organização: em relação a esse último cita-se o mercado competitivo e os padrões contábeis exigidos. Em relação aos mecanismos internos de controle de governança corporativa, identifica-se a estrutura de propriedade como o principal, especialmente em países com alta concentração de propriedade.

A literatura coloca que a concentração acionária proporciona tanto custos (efeito entrincheiramento), quanto benefícios 
(efeito alinhamento) e pode ser causada por fatores, tais como, tamanho da empresa, instabilidade do mercado e estrutura de capital. As vantagens mais discutidas direcionadas à concentração de propriedade estão ligadas à possibilidade dos proprietários melhor monitorar a administração com a provável redução de conflitos e custos de agência. Em relação aos custos provenientes da concentração acionária, ressalta-se que acionistas controladores expropriam a riqueza dos outros acionistas de várias formas, tais como, pagamentos de salários excessivos para si, autonomeação em cargos executivos privilegiados e posições no conselho para si, familiares ou parentes (nepotismo) e, pagam ou recebem preços de transferências altos para empresas das quais são proprietários. Nesse caso, os benefícios privados do controle podem levar investidores a se assegurarem de retornos através de mecanismos que lhes confiram o controle corporativo.

Ademais, coloca-se ainda que, em função da aversão ao risco, grandes empresas tendem a apresentar uma baixa concentração da propriedade e os conflitos de interesses são menores ou maiores dependendo da instabilidade dos mercados. A redução do grau de instabilidade do mercado provoca a redução da concentração da propriedade, podendo, inclusive, aumentar a liberdade de monitoramento dos gestores. Entretanto, a estrutura de capital pode afetar negativamente ou positivamente a concentração de propriedade - efeito negativo devido ação dos acionistas controladores compartilhar os riscos, e efeito positivo devido os ativos específicos.

Esse trabalho teve por objetivo, em uma amostra de 176 empresas não-financeiras com ações negociadas na Bovespa no período de 1997 a 2001, analisar se existe relação entre o grau de concentração acionária e: a) performance das empresas (rentabilidade do patrimônio líquido, crescimento da receita líquida e $\mathrm{Q}$ de Tobin); b) instabilidade do mercado; c) estrutura de capital; e d) tamanho do ativo. Procedendo a categorização do grau de concentração acionária em dispersa, dominante e majoritária, como proposta por Pendersen e Thomsen (1997), empregouse a Análise de Variância (ANOVA) e o Teste de Kruskal-Wallis.

Os resultados indicaram que não há relação entre o grau de concentração e rentabilidade do patrimônio líquido, Q de Tobin (valor das empresas), estrutura de capital e tamanho do ativo, nas empresas não-financeiras de capital aberto no Brasil. Por outro lado, as evidências direcionam pela existência de relação entre concentração de propriedade e crescimento da receita líquida e instabilidade do mercado. Desse modo, considerando o crescimento da receita líquida como medida de performance nota-se que essa é menor para empresas dispersas, maior para empresas dominantes e para empresas majoritárias, sendo relativamente maior para empresas dominantes que para empresas majoritárias. No que concerne a instabilidade do mercado, os resultados encontrados estão de acordo com Demsetz e Lehn (1985) e Pedersen e Thomsen (1997), os quais identificaram correlação positiva entre a instabilidade da rentabilidade e a concentração da propriedade.

A não evidência de relação estatística entre o grau de concentração e rentabilidade do patrimônio líquido, Q de Tobin (valor das empresas), estrutura de capital e tamanho do ativo pode ter acontecido por dois motivos: 1) a própria classificação da concentração de propriedade como proposto por Pedersen e Thomsen (1997) pode estar não condizente com a realidade brasileira, carecendo de uma classificação mais equânime; e 2) o processo de considerar a média do período 1997-2001 pode ocultar algumas características dos dados. Nesse sentido, sugere-se em pesquisas posteriores o uso de outra classificação de propriedade e/ou métodos estatísticos de Análise de Regressão, tal como Mínimos Quadrados Ordinários, que tratem os dados simplesmente como intervalares. Ademais, o uso de um período maior da amostra e/ou a mesma amostra, entretanto não considerando a média do período mais os desvios em relação à média (efeitos fixos), podem trazer resultados mais robustos estatisticamente.

\section{REFERÊNCIAS}

ANDRADE, A.;ROSSETTI, J. P. Governança Corporativa. São Paulo: Atlas, 2004.

BARNEY, J. B. Gaining and Sustaining Competitive Advantage. Reading, MA: Addison Wesley Publishing Company, 1997.

BUSSAB, W. Análise de Variância e Regressão. São Paulo: Saraiva, 1999.

CAMPOS, H. Estatística Experimental Não-Paramétrica. 4 ed. São Paulo: ESA "Luiz de Queiroz" - USP, 1983.

CARVALHAL-DA-SILVA, A. L. Governança corporativa, valor, alavancagem e política de dividendos das empresas brasileiras. Revista de Administração da USP (RAUSP), São Paulo, v.39, n.4, p.348361, out/nov/dez. 2004.

CHUNG, K; PRUITT, S. A simple approximation of Tobin's Q. Financial Management, v.23, n.3, p.70-74, Autumn, 1994.

CLAESSENS, S.; DJANKOV, S.; FAN, J.P.H.; LANG, L. Disentangling the incentive and entrenchment of large shareholdings. The Journal of Finance, v.LVII, n.6, p.2741-2771, Dec. 2002.

CONOVER, W. J. Practical nomparametric statistics. Second Edition, New York: John Wiley \& Sons, 1980.

DEMSETZ, H.; LEHN, K. The structure of corporate ownership: causes and consequences. Journal of Political Economy, v.93, n.6, p.11551177, Dec. 1985.

DEMSETZ, H.; VILLALONGA, B. Ownership structure and corporate performance. Journal of Corporate Finance, v.7, n.3, p.209233, Sep. 2001.

FAMÁ, R.; BARROS, L.A.B. Q de Tobin e seu uso em finanças: aspectos metodológicos e conceituais. Caderno de Pesquisas em Administração, São Paulo, v.7, n.4, out/dez 2000.

HITT, M. A.; HOSKISSON, R. E.; IRELAND, R. D. Administração estratégica. São Paulo: Pioneira Thomson Learning, 2002.

JENSEN, M. C.; MECKLING, W. H. Theory of the firm: managerial behavior, agency costs and ownership structure. Journal of Financial Economics, v.3, p.305-360, jul. 1976.

LA PORTA, R.; LOPEZ-DE-SILANES, F.; SHLEIFER, A.; VISHNY, R. Law and finance. Journal of Political Economy, Chicago, v.106, n.6, p.1113-1155, dec. 1998.

Corporate ownership around the world. Journal of Finance, Malden, v.54, n.2, p.471-518, apr. 1999.

LEAL, R. P. C.; CARVALHAL, A.; ALOY JUNIOR, R.; LAPAGESSE, G.; Estrutura de controle e valor de mercado das empresas brasileiras. In: ENCONTRO NACIONAL DE PÓS-GRA- 
DUAÇÃO EM ADMINISTRAÇÃO,24 , 2000, Florianópolis, Anais ... 2000. CD-ROM.

OKIMURA, R. T. Estrutura de propriedade, governança corporativa, valor e desempenho das empresas no Brasil. São Paulo: 2003. Dissertação de Mestrado apresentada a FEA/USP.

OKIMURA, R. T.; SILVEIRA, A. M.; ROCHA, K. C. Estrutura de propriedade e desempenho corporativo no Brasil. In: ENCONTRO NACIONAL DE PÓS-GRADUAÇÃO EM ADMINISTRAÇÃO, 28, 2004, Curitiba, Anais... 2004. CD-ROM.

PEDERSEN, T.; THOMSEN, S. European patterns of corporate ownership: a twelve-country study. Journal of International Business Studies, v.28, n.4, p.759-778, Fourth Quarter, 1997.

SHLEIFER, A.; VISHNY, R. W. A survey of corporate governance. Journal of Finance, v.52, 1997.

SIEGEL, S. Estatística Não-Parmétrica para as Ciências do Comportamento. São Paulo: MacGraw-Hill do Brasil Ltda, 1975.

SIFFERT FILHO, N. F. Governança Corporativa: Padrões Internacionais e Evidências Empíricas no Brasil nos anos 90. Revista do BNDES, Rio de Janeiro, v.5, no 9. jun, 1998.

SILVEIRA, A. M. Governança corporativa e estrutura de propriedade: determinantes e relação com o desempenho no Brasil. São Paulo: 2004. Tese de Doutoramento apresentado a FEA/USP.

SILVEIRA, A. M. Governança Corporativa, Desempenho e Valor da Empresa. São Paulo: 2002. Dissertação de Mestrado apresentado a FEA/USP.

SILVEIRA, A. M.; BARROS, L. A. B.; FAMÁ, R. Atributos corporativos, qualidade da governança corporativa e valor das companhias abertas no Brasil. In: ENCONTRO BRASILEIRO DE FINANÇAS, Anais ... 2005. CD-ROM.

SIQUEIRA, T. V. Concentração da Propriedade nas Empresas Brasileiras de Capital Aberto. Revista do BNDES. Rio de Janeiro, v. 5, $\mathrm{n}^{\circ}$ 10, p.37-62, dez. 1998. 